\title{
Temporal discounting and attention-deficit/hyperactivity disorder in childhood: reasons for devising different tasks
}

\author{
Desconto do futuro e o transtorno de déficit de atenção/hiperatividade: \\ razões para o desenvolvimento de diferentes tarefas
}

\author{
Daniel Augusto Utsumi, ${ }^{1}$ Mônica Carolina Miranda²
}

\begin{abstract}
Introduction: Temporal discounting (TD) describes how a certain reward is seen as less valuable the more its delivery is postponed. There are two main types of TD tasks, hypothetical and real, both of which use monetary rewards. Over the last few years, however, variants of these tasks have been adjusted to assess clinical groups of children showing impulsivity as found in attention-deficit/hyperactivity disorder (ADHD).

Objective: To review and discuss studies conducted over the last 10 years on the use of TD tasks in the assessment of pediatric patients with ADHD.

Method: For this literature review, articles were nonsystematically selected from PubMed, MEDLINE and SciELO databases to include experimental studies on the use of at least one TD paradigm to assess and distinguish ADHD and non-ADHD groups.

Results: Of the studies assessed, $76.19 \%$ used hypothetical tasks, followed by real tasks (28.57\%), and, finally, tasks using different types of reward, such as toys or rewarding activities (14.28\%).

Conclusions: Although assessed in few studies, real and alternative tasks appeared to be effective in differentiating clinical groups and suitable for investigating hot executive functions in childhood.
\end{abstract}

Keywords: ADHD, temporal discounting, hypothetical task, real task, children.

\section{Resumo}

Introdução: O desconto do futuro (DF) é um processo no qual uma determinada recompensa é vista como menos valiosa à medida que sua entrega é postergada. Existem dois tipos principais de tarefas de DF, hipotéticas e reais, sendo que ambas usam recompensas monetárias. Nos últimos anos, no entanto, variantes dessas tarefas têm sido adaptadas para avaliar grupos clínicos de crianças que apresentam comportamento impulsivo, como no caso do transtorno de déficit de atenção/hiperatividade (TDAH).

Objetivo: Revisar e discutir os estudos realizados nos últimos 10 anos sobre o uso de tarefas de DF na avaliação de pacientes pediátricos com TDAH.

Método: Para esta revisão de literatura, os artigos foram selecionados de forma não sistemática nas bases de dados PubMed, MEDLINE e SciELO, de forma a incluir estudos experimentais sobre o uso de ao menos um paradigma de DF para a avaliação e distinção de grupos com e sem TDAH.

Resultados: Dos estudos avaliados, $76,19 \%$ utilizaram tarefas hipotéticas, seguidas de tarefas reais $(28,57 \%)$ e, finalmente, de tarefas com diferentes tipos de recompensa, como brinquedos ou atividades recompensadoras (14,28\%).

Conclusões: Embora avaliadas em poucos estudos, tarefas reais e alternativas parecem ser eficazes na diferenciação de grupos clínicos e adequadas para investigação de funções executivas quentes na infância.

Descritores: TDAH, desconto do futuro, tarefa hipotética, tarefa real, crianças.

\footnotetext{
${ }^{1}$ Departamento de Psicobiologia, Universidade Federal de São Paulo (UNIFESP), São Paulo, SP, Brazil. ${ }^{2}$ Programa de Mestrado em Psicossomática, Universidade Ibirapuera, São Paulo, SP, Brazil.

The present article was based on the first author's dissertation, entitled "Adiamento de recompensa e a autorregulação emocional em crianças com transtorno de déficit de atenção/hiperatividade."

Submitted Jul 21 2017, accepted for publication Nov 212017.

Suggested citation: Utsumi DA, Miranda MC. Temporal discounting and attention-deficit/hyperactivity disorder in childhood: reasons for devising different tasks. Trends Psychiatry Psychother. 2018;40(3):248-252. http://dx.doi.org/10.1590/2237-6089-2017-0094
} 


\section{Introduction}

Temporal discounting (TD) refers to tendency of rewards to be discounted the more their delivery is delayed. ${ }^{1,2}$ Initially designed for the assessment of adults, in recent years this paradigm has helped draw important parallels between emotion and decision-making ${ }^{3}$ in neurodevelopmental disorders marked by impulsivity, including attention-deficit/hyperactivity disorder (ADHD). ${ }^{4}$ Research shows that patients with ADHD have higher TD rates than typically developing individuals, ${ }^{4-11}$ especially among younger children as compared to adolescents and adults. ${ }^{12,13}$ These data are reinforced by neuroimaging studies that have detected alterations in circuits associated with encoding rewards and intertemporal choice in patients with ADHD during TD tasks. ${ }^{11,14}$

Essentially, TD tasks consist of a series of trials offering a choice between a small immediate reward and a large one delivered after a certain delay. ${ }^{1,15}$ Varying the range of immediate rewards and delays obviously requires an increased number of trials to obtain averages. After tasks are completed, the level of discounting may be calculated for each choice, based on specific parameters. The free parameter $\mathrm{k}$ reflects the sensitivity for delayed reinforcers, ${ }^{1,16}$ but many studies have used the indifference point at which a subject no longer shows any preference between waiting for a larger reward or taking an immediate smaller one. ${ }^{17}$ By determining a set of indifference points for each delay, the total discounting rate may be estimated by calculating the area under the curve (AUC)..$^{10,17}$

There are basically three types of TD tasks: hypothetical, real, and those that will here be called alternative tasks. The former uses longer delays, ranging from days to weeks, and larger monetary rewards. Real tasks are formally very similar to hypothetical ones and also involve monetary rewards, but rewards are actually delivered and time intervals may be experienced..$^{10}$ Unlike studies using hypothetical tasks, real tasks commonly use smaller rewards (a few cents) and shorter delays (from a few seconds to a few minutes). Alternative tasks may feature combinations of hypothetical and/or real tasks and rewards such as toys, food, or rewarding activities.

Of the many theories attempting to explain the performance of patients with ADHD on TD tasks, the delay aversion model is one of the most widely used. This model gives special emphasis on the behavioral aspect and states that preference for immediate reward is motivated by the desire to avoid experiencing negative emotional states associated with enforced waiting. ${ }^{18-20}$ More recently, Sonuga-Barke \& Fairchild ${ }^{21}$ have also developed a decision-making model based on psychiatric neuroeconomics, which posits that deficits of patients with ADHD on TD tasks arise from dysfunctions in three distinct but correlated brain circuits: 1) prospective, involving the default network; 2) the reward circuit; and 3 ) the executive network. ${ }^{22}$

It is important to note that variables such as age, type of tasks, magnitude of the reward, length of delay, and symptomatological characteristics are fundamental to better adjust TD tasks to children's preferences, ensuring more consistent results based on neurodevelopmental stages.

In view of the foregoing, several variables should be considered when devising TD tasks, especially the age of the participants, symptomatological characteristics, types of tasks, and models employed. Thus, the present study reviews research published in the last 10 years on the use of TD paradigms to assess patients with ADHD, analyzing the influence of the factors mentioned above on the differentiation of the experimental groups.

\section{Method}

This study is a narrative review. Articles on the use of TD tasks to assess ADHD published between January 2006 and July 2017 were non-systematically selected from the PubMed, MEDLINE and SciELO databases. The terms "ADHD AND (Temporal OR Delay) Discounting" were used in the search.

The following eligibility criteria were observed: experimental studies that used at least one TD task to assess ADHD and control groups not using methylphenidate. Reviews, studies that did not evaluate ADHD or emphasized the investigation of other disorders, research with animals, studies lacking information about tasks and results, and articles in languages other than English, Portuguese and Spanish were excluded.

\section{Results}

Articles whose title did not meet the eligibility/ exclusion criteria at first reading were automatically excluded. Of the remaining articles, many were excluded after reading the abstract, and a smaller portion after reading the full text. A total of 21 articles met the eligibility criteria explained above, i.e., experimental studies on the use of TD tasks in ADHD and control groups not using medication. Figure 1 shows the flowchart for study selection. Sixteen studies (76.19\%) used hypothetical monetary tasks. Of these, $9(56.26 \%)$ found differences between patients with 
ADHD and controls, regardless of age. $4,5,7,8,11,23-26$ In terms of age groups, 9 studies evaluated only children and adolescents. ${ }^{4,6-8,11,22,26-28}$ Five of these (55.55\%) were successful in distinguishing ADHD from nonADHD groups. ${ }^{4,6,8,11,29}$ One found a slight difference between ADHD and control groups, which did not resist covariation with intelligence quotient (IQ). ${ }^{7}$ Of the four studies that evaluated adults alone, $5,14,23,30$ two (50\%) were able to distinguish between patients with ADHD and controls, 5,23 and the two studies covering a wider range of age groups (children, adolescents, and adults) were also capable of distinguishing individuals with ADHD from healthy ones. ${ }^{25,26}$

The six studies $(28.57 \%)$ that used real monetary tasks evaluated only children and adolescents (Figure 1). It is important to note that some of them also applied hypothetical tasks and were previously described here. Of these, three (50\%) studies were able to differentiate between ADHD and control groups consisting of children and adolescents, ${ }^{8,9,22}$ especially between patients with combined ADHD presentation and controls. 8,9 The other three studies found no differences between groups. 26,31,32 However, two of these used even smaller rewards and shorter delays than the conventional ones for this type of task. ${ }^{26,32}$
Only three (14.28\%) studies used alternative tasks. One applied a task with hypothetical monetary reward and a real-time task with consumable rewards, ${ }^{33}$ but only the latter yielded between-group differences, which were attributed to the interaction between group and sex. Another study used three types of tasks with toys as rewards: hypothetical, real, and a new type entitled as hypothetical with temporal expectation, in which toys were not delivered but delays could be experienced. ${ }^{34}$ This was the only task that showed significant betweengroup differences. Both studies covered the same age group, i.e., 8-12 years old. Demurie et al. ${ }^{6}$ assessed participants aged 8-16 years using other types of rewards, such as edibles, social gains, material rewards, and gratifying activities, but did not find between-group differences, although they found that monetary rewards and material gains such as toys showed similar levels of reinforcement.

\section{Discussion}

As predicted, hypothetical tasks with monetary rewards were the most widely used, followed by real tasks with monetary rewards and, finally, alternative

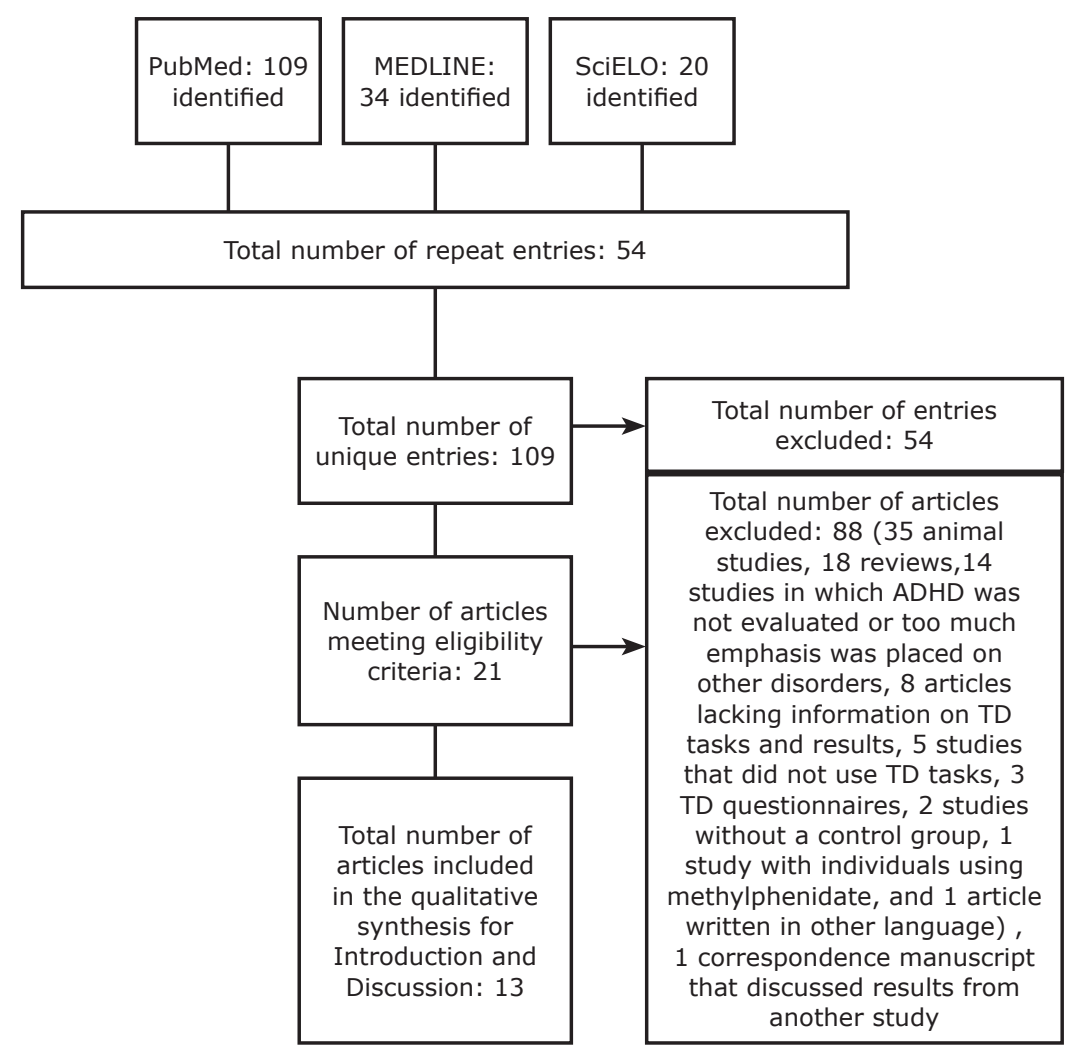

Figure 1 - Study selection process across different stages of the review 
tasks. Hypothetical and real tasks were similar in terms of differentiation between ADHD and control groups in childhood. Despite the small number of studies, real and alternative tasks held promise for assessing children and adolescents.

Differences between ADHD and non-ADHD groups appear to be more pronounced among younger children. This may be related to the notion that the processes involved in decision-making depend on the maturation of executive functions, which takes place most intensely from adolescence onwards due to remodeling of the dopaminergic and reward systems, as highlighted by a relevant review. ${ }^{12} \mathrm{~A}$ meta-analytic review conducted by Pauli-Pott et al. ${ }^{12}$ showed significant differences between ADHD and control groups, especially in preschoolers as compared to school-age and adolescents participants.

Together with this factor, type of task may or may not favor assessment of children. According to SonugaBarke \& Fairchild, ${ }^{21}$ hypothetical tasks would involve much more prospective activity in comparison with real tasks, requiring the individual to create subjective projections about the future and consequently more sophisticated considerations.

This hypothesis certainly poses a more persuasive explanation than the delay aversion model, especially given the data reported by Scheres et al., ${ }^{8}$ who have experimentally shown that high TD rates are not necessarily linked to a waiting aversive notion. In addition, the delay aversion model seems to be more concerned with the hyperactivity-impulsivity, rather than the inattention, observed in ADHD. In this respect, studies show that hyperactivity-impulsivity symptoms predict high discounting rates on TD tasks, whereas inattention symptoms do not. ${ }^{8,9,11}$ This point, in addition to the age-related performance differences found between ADHD and control groups, may indicate that children with combined ADHD presentation are more likely to present impairments in TD tasks, although this is not an absolute fact. Scheres et al., ${ }^{32}$ for example, also found performance differences among children and adolescents in TD tasks, but not between ADHD and control groups. Thus, other factors are equally fundamental for the design of effective tasks for the differentiation of clinical groups.

An important aspect is how length of delay and magnitude of reward affect TD tasks. As mentioned above, real and hypothetical tasks differ in magnitude of reward and length of delay, ${ }^{22,34}$ since using large amounts of money and long intervals is not practical for real tasks. However, a key question is to what extent delays and rewards may be diminished while still triggering impulsive responses. This explains why the two studies that used smaller rewards failed to detect intragroup differences. ${ }^{26,32}$
In addition to the magnitude of rewards, the type of reward used for tasks is a key aspect, since monetary tasks have been created to assess adults. TD tasks have also been adapted, as shown by studies involving alternative tasks. ${ }^{6,33,34}$ Regardless of the results, these studies have demonstrated that other types of rewards trigger behavioral responses such as those observed when using money in children and adolescents. In addition, the study by Utsumi et al. ${ }^{34}$ demonstrated the effectiveness of a new type of task called hypothetical with temporal expectation.

When discussing these experiments, a relevant question arises in relation to the subjective value posed by non-monetary rewards. Although two of the studies had previously sought to assign objective value to rewards, ${ }^{6,34}$ this issue may be the main bias that limits the use of alternative rewards in TD studies. At the same time, these studies favor the delineation of new tasks, which are similar to daily decision-making situations.

The present study shows that, despite their infrequent use, real tasks with monetary rewards are as effective as hypothetical tasks when assessing intertemporal choice in patients with ADHD based on the neurodevelopmental stages of executive functions. In addition, this study highlights the importance of reexamining length of delay and magnitude and type of reward to devise more appropriate tasks for children's preferences.

\section{Disclosure}

No conflicts of interest declared concerning the publication of this article.

\section{References}

1. Killeen PR. An additive-utility model of delay discounting. Psychol Rev. 2009;116:602-19.

2. Peters J, Büchel C. The neural mechanisms of inter-temporal decision-making: understanding variability. Trends Cogn Sci. 2011;15:227-39.

3. Wittmann M, Lovero KL, Lane SD, Paulus MP. Delayed rewards. 2011;3:15-26.

4. Demurie E, Roeyers H, Baeyens D, Sonuga-Barke E. Temporal discounting of monetary rewards in children and adolescents with ADHD and autism spectrum disorders. Dev Sci. 2012;15:791800.

5. Hurst RM, Kepley HO, McCalla MK, Livermore MK. Internal consistency and discriminant validity of a delay-discounting task with an adult self-reported ADHD sample. J Atten Disord; 2011;15:412-22.

6. Demurie E, Roeyers H, Baeyens D, Sonuga-Barke E. Domaingeneral and domain-specific aspects of temporal discounting in children with ADHD and autism spectrum disorders (ASD): A proof of concept study. Res Dev Disabil. 2013;34:1870-80.

7. Wilson VB, Mitchell SH, Musser ED, Schmitt CF, Nigg JT. Delay discounting of reward in ADHD: application in young children. J Child Psychol Psychiatry. 2011;52:256-64. 
8. Scheres A, Tontsch C, Thoeny AL. Steep temporal reward discounting in ADHD-Combined type: acting upon feelings. Psychiatry Res. 2013;209:207-13.

9. Scheres A, Tontsch C, Thoeny AL, Kaczkurkin A. Temporal reward discounting in attention-deficit/hyperactivity disorder: the contribution of symptom domains, reward magnitude, and session length. Biol Psychiatry. 2010;67:641-8.

10. Scheres A, Sumiya M, Thoeny ALEE. Studying the relation between temporal reward discounting tasks used in populations with ADHD: a factor analysis. 2010;19:167-76.

11. Dias TGC, Wilson VB, Bathula DR, Iyer SP, Mills $L$, Thurlow BL, et al. NIH Public Access. 2014;23:33-45.

12. Pauli-Pott $U$, Becker K. Time windows matter in ADHD-related developing neuropsychological basic deficits: A comprehensive review and meta-regression analysis. Neurosci Biobehav Rev. 2015;55:165-72.

13. Patros CHG, Alderson RM, Kasper LJ, Tarle SJ, Lea SE, Hudec $\mathrm{KL}$. Choice-impulsivity in children and adolescents with attentiondeficit/hyperactivity disorder (ADHD): A meta-analytic review. Clin Psychol Rev. 2016;43:162-74.

14. Wilbertz G, Trueg A, Sonuga-Barke EJS, Blechert J, Philipsen A, Tebartz van Elst L. Neural and psychophysiological markers of delay aversion in attention-deficit hyperactivity disorder. J Abnorm Psychol. 2013;122:566-72.

15. Tesch AD, Sanfey AG. Models and methods in delay discounting. Ann N Y Acad Sci. 2008;1128:90-4.

16. Critchfield TS, Kollins SH. Temporal discounting: basic research and the analysis of socially important behavior. J Appl Behav Anal. 2001;34:101-22.

17. Myerson J, Green L, Warusawitharana M. Area under the curve as a measure of discounting. J Exp Anal Behav. 2001;76:235-43.

18. Sonuga-Barke EJS, Sergeant J a., Nigg J, Willcutt E. Executive Dysfunction and Delay Aversion in Attention Deficit Hyperactivity Disorder: Nosologic and Diagnostic Implications. Child Adolesc Psychiatr Clin N Am. 2008;17:367-84.

19. Sonuga-Barke EJS. The dual pathway model of $A D / H D$ : An elaboration of neuro-developmental characteristics. Neurosci Biobehav Rev. 2003;27:593-604.

20. Bitsakou P, Psychogiou L, Thompson M, Sonuga-Barke EJS. Delay Aversion in Attention Deficit/Hyperactivity Disorder: an empirical investigation of the broader phenotype. Neuropsychologia. 2009;47:446-56.

21. Sonuga-Barke EJS, Fairchild G. Neuroeconomics of attentiondeficit/hyperactivity disorder: Differential influences of medial, dorsal, and ventral prefrontal brain networks on suboptimal decision making? Biol Psychiatry; 2012;72:126-33.

22. Yu X, Sonuga-Barke E. Childhood ADHD and Delayed Reinforcement: A Direct Comparison of Performance on Hypothetical and Real-Time Delay Tasks $\backslash r \backslash n$. J Atten Disord. 2016;1-9.

23. Dai Z, Harrow S-E, Song X, Rucklidge J, Grace R. Gambling, delay, and probability discounting in adults with and without ADHD. J Atten Disord. 2016;20:968-78.
24. Yu X, Sonuga-Barke E, Liu X. Preference for Smaller Sooner Over Larger Later Rewards in ADHD: Contribution of Delay Duration and Paradigm Type. J Atten Disord. 2015 Feb, 11.

25. Fassbender C, Houde S, Silver-Balbus S, Ballard K, Kim B, Rutledge $\mathrm{KJ}$, et al. The decimal effect: behavioral and neural bases for a novel influence on intertemporal choice in healthy individuals and in ADHD. J Cogn Neurosci. 2014;26:2455-68.

26. Paloyelis $Y$, Asherson P, Mehta MA, Faraone SV, Kuntsi J. DAT1 and COMT effects on delay discounting and trait impulsivity in male adolescents with attention deficit/hyperactivity disorder and healthy controls. Neuropsychopharmacology. Neuropsychopharmacology. 2010;35:2414-26.

27. Antonini TN, Becker SP, Tamm L, Epstein JN. Hot and Cool Executive Functions in Children with Attention Deficit/Hyperactivity Disorder and Comorbid Oppositional Defiant Disorder. 2016;116:1477-90.

28. Chantiluke K, Christakou A, Murphy CM, Giampietro V, Daly EM, Ecker C, et al. Disorder-specific functional abnormalities during temporal discounting in youth with Attention Deficit Hyperactivity Disorder (ADHD), Autism and comorbid ADHD and Autism. Psychiatry Res. 2014;223:113-20.

29. Costa Dias TG, Iyer SP, Carpenter SD, Cary RP, Wilson VB, Mitchel $\mathrm{SH}$, et al. Characterizing heterogeneity in children with and without ADHD based on reward system connectivity. Dev Cogn Neurosci . 2015;11:155-74.

30. Wilbertz G, van Elst LT, Delgado MR, Maier S, Feige B, Philipsen $A$, et al. Orbitofrontal reward sensitivity and impulsivity in adult attention deficit hyperactivity disorder. Neuroimage. 2012;60:353-61.

31. Krause-Utz A, Cackowski S, Daffner S, Sobanski E, Plichta MM, Bohus $M$, et al. Delay discounting and response disinhibition under acute experimental stress in women with borderline personality disorder and adult attention deficit hyperactivity disorder. Psychol Med. 2016;1-13.

32. Scheres A, Dijkstra M, Ainslie E, Balkan J, Reynolds B, SonugaBarke $E$, et al. Temporal and probabilistic discounting of rewards in children and adolescents: effects of age and ADHD symptoms. Neuropsychologia. 2006;44:2092-103.

33. Rosch KS, Mostofsky SH. Increased Delay Discounting on a Novel Real-Time Task among Girls, but not Boys, with ADHD. J Int Neuropsychol Soc. 2016;22:12-3.

34. Utsumi DA, Miranda MC, Muszkat M. Temporal discounting and emotional self-regulation in children with attention-deficit/ hyperactivity disorder. Psychiatry Res. 2016; 30;246:730-737.

\section{Correspondence:}

Mônica C. Miranda

Rua Embaú, 54, Vila Clementino

04029-060 - São Paulo, SP - Brazil

Tel. : +55 (11) 55496899

E-mail: mirandambr@yahoo.com.br 